\title{
Article
}

\section{Fit to Race: Identifying the balance, type and sources of knowledge in fitness for Motorsport}

Hoyes, K., and Collins, D.

Available at http://clok.uclan.ac.uk/22049/

Hoyes, K., and Collins, D. ORCID: 0000-0002-7601-0454 (2018) Fit to Race: Identifying the balance, type and sources of knowledge in fitness for Motorsport. International Journal of Sports Science and Coaching, 13 (5). pp. 751-760. ISSN 1747-9541

It is advisable to refer to the publisher's version if you intend to cite from the work. http://dx.doi.org/10.1177/1747954118758277

For more information about UCLan's research in this area go to http://www.uclan.ac.uk/researchgroups/ and search for <name of research Group>.

For information about Research generally at UCLan please go to http://www.uclan.ac.uk/research/

All outputs in CLoK are protected by Intellectual Property Rights law, including Copyright law. Copyright, IPR and Moral Rights for the works on this site are retained by the individual authors and/or other copyright owners. Terms and conditions for use of this material are defined in the policies page.

\section{CLoK}

Central Lancashire online Knowledge www.clok.uclan.ac.uk

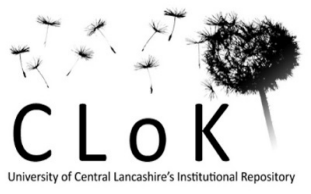


Running head: Fitness for Motorsport

Fit to Race: Identifying the balance, type and sources of knowledge in fitness for Motorsport

Kevin Hoyes ${ }^{1} \&$ Dave Collins ${ }^{1,2,3}$

1: iZone Driver Performance Ltd.

2: Institute of Coaching and Performance, University of Central Lancashire, UK

3: Grey Matters Performance Ltd, Stratford Upon Avon, UK. 


\begin{abstract}
In Motorsport, due perhaps to a lack of empirical evidence, it is not always clear what fitness training is required and what roles specific fitness components play, particularly outside the elite levels. Consequently, drivers and their trainers are often left to their own devices, placing reliance on anecdotal information. Accordingly, using a large sample of racing drivers, coaches and fitness trainers, the aim of this investigation was to identify the perceived importance and contribution of fitness components, the sources of information used to reach these conclusions and levels of confidence in the views reported. Survey data from 166 drivers (151 males, 15 females) showed that, in general, cardiovascular fitness, upper body strength, coordination and reactions were perceived as being the most important. Data on sources of information used supported the conjecture that training can often be based on "word of mouth". Despite a fairly high level of confidence in the views expressed, there is clearly a significant opportunity for practitioners working within Motorsport to provide clearer, proven information so that drivers can feel confident that they are training optimally.
\end{abstract}

Keywords Cardiovascular endurance, strength, power, racing drivers, performance 


\section{Introduction}

Within Motorsport there appears to be a consensus that fitness is an important factor, with many drivers anecdotally commenting on the physical challenges faced [e.g. 1,2] and several fitness-related articles apparent in newspapers or magazines [e.g. 3, 4]. Despite this, however, drivers have rarely been subject to scientific research [5]. This could partly be due to data from elites not making its way to refereed journals, or filtering down to other levels. For example, we are aware that driver monitoring is used in Formula One (F1) and World Rally Championship (WRC), to help design driver's training, but none of this is actually published: understandably so as drivers and teams are trying to establish an advantage over their competitors. This is not to say that scientific data does not exist, there have been studies that have analysed driving performance [6], monitored drivers' in car [7-10] and those which have investigated the physical characteristics of racing drivers [11-13]. However, these didn't provide training history of the drivers, so it is unclear if these are adaptations or characteristics required for their sport, or results of their chosen training practices. In terms of practical guidance for drivers, trainers and coaches there are only Ebben's [14] suggestions for stock car racing and Jutley and Blow's [15] book with very general information. Therefore, it appears that many drivers base their fitness training on information or, perhaps, just rumour, from other sources. Accordingly, this investigation was set out to discover what is perceived to be important and why, together with which sources are used to obtain this information. Previous studies have tended to focus on small groups of drivers in a specific formula, for example Ebben and Suchomel's [2] focus on stock car racing. The authors are unaware of any other surveys being completed on a large scale and across different formulas of racing. As such, an initial descriptive investigation seemed warranted.

Arguably, the key parameter is the relative balance of fitness components, together with the extent to which these are agreed upon or disparate across formulas and individuals. 
For training to have optimum impact in any sport, knowledge of specific parameters, training methods and exercises that fulfil the criteria for specificity are required [16, 17]. Slight modifications to training balance between components may also be required, depending on the role or discipline within a single sport; for example, training prescribed based on playing position in soccer [18]. In this respect, Motorsport is particularly unique due to the wide range of different events and vehicles [19]. To name just a few, Karting, Touring Cars, GT, Single Seaters and Rallying, all of which vary in duration and intensity. Table 1 presents a simple comparison across several disciplines in order to exemplify this variation within the overarching category of Motorsport fitness.

$$
* *[\text { Table } 1 \text { here }]^{* *}
$$

As a further complication, fitness in Motorsport potentially serves a dual purpose; the enhancement of performance and the protection of wellbeing in the athlete. Reflecting this, we have suggested two categories of fitness components: firstly, "hygiene factors", which can be described as factors which are only needed to a certain level, to prevent injury or to counteract negatives in performance. Secondly, and as a sometimes overlapping but usually distinct group, there are "performance factors", which contribute directly to the outcome. Simply, the more an individual has the better for their performance. These terms are now included in the UK Motor Sport Association's (MSA's) coaching scheme. It has been suggested that the initial focus of fitness training in Motorsport was driver safety after Nelson Piquet collapsed on the podium in 1982 [15], so perhaps this may have led to an emphasis on "hygiene factors". Accordingly, it was of interest to discover what factors are believed to be important for drivers' performance and protection.

As well as finding out what people think, it's also important to know why they think it. This becomes particularly important if those working within this field wish to influence or 
modify perceptions. Another important and parallel element is confidence in what individuals know. If they are unsure of the knowledge, there is a greater potential for change than if they were certain. In order to get the widest possible perspective on this, an online survey was selected to provide a broad range of data.

So, reflecting the concerns and issues identified above, the following issues were addressed:

1. Participants' perceived importance of different fitness components, the balance between them and the extent to which this varied across formulas.

2. The balance of opinion on the perceived role of these factors (i.e. performance vs. hygiene).

3. The sources of information participants used to reach these conclusions.

4. The levels of confidence in these views reported by participants across the piece.

\section{Method}

Participants

Participants were recruited using three approaches. Firstly, by an email sent out to the iZone Driver Performance database. This contained a participant information sheet explaining the survey and a link taking those interested to the introduction page. This page indicated that completing the survey would represent their consent to participate. Secondly, convenience sampling was used to recruit drivers attending iZone for training sessions. During their visit, drivers were invited to participate in the online survey using a web link on a tablet. Subsequently, when completing the survey, participants were left alone to avoid any influence on the answers given. Thirdly, the same email invitation detailed above was sent out by the MSA to their database. The study protocol for all three categories was reviewed 
and approved by the University's Research Ethics Committee. These three processes resulted in 166 responses, from a wide range of driver ability, achievement and support profession.

\section{Instrumentation}

A twenty-page online survey was developed to obtain demographic information and to establish the level and sources of knowledge on fitness in a sample of Motorsport participants (drivers, coaches, fitness trainers, mechanics and engineers) across formulas. As the first step, questions were generated against the specific objectives outlined above. Piloting was then completed with a sample of eight participants, who completed the questionnaire then subsequently interviewed on the process to check levels of clarity and understanding. This led to some minor changes in wording, but the instrument as a whole remained unchanged. The questionnaire included three sections: (1) about the participant, which identified the amount and level of experience participants had in Motorsport as a driver, coach or fitness trainer; (2) what physical fitness components are important and why, in which participants were asked to rate the importance of each fitness component for their formula as a percentage, summing to a total of $100 \%$ as well as to indicate whether they believed each component to be a "hygiene factor" or a "performance factor" and; (3) sources of information used to inform decision making and opinion. The survey took approximately twenty minutes to complete and is included as Appendix 1.

\section{Design}

Given the preliminary nature of the investigation, this study was seen as primarily descriptive. Accordingly, subsets of the full data set were used to address the 4 purposes identified in the introduction. Where appropriate, non-parametric statistical tests (the Chi Square or $\mathrm{X}^{2}$ (with probability value set at $\mathrm{p}<.05$ ) were used with SPSS software to examine the degree and nature of differences. 


\section{Results}

\section{Demographics}

There were 166 respondents of which 110 completed the full survey; all the available data were used, so that the numbers of respondents varied between these figures across the survey. There were 151 males and 15 females with a mean age of 32.4 (SD 14.8) with the youngest respondent being 14 and the eldest 73 . Table 2 shows the levels of experience reported, either as drivers and/or other roles within Motorsport. The vast majority of participants had racing driver experience (151). Participants were allowed to select more than one role, so some reported multiple experiences; for example, a driver who also did coaching. As the statistics suggest, these were very skewed by a few individuals with long periods of experience whilst the majority had more homogenous levels of involvement. Those with driver coach or fitness trainer experience had worked with an average of 12 drivers in the previous 12 months (SD 18.72 , range 80$)$.

$$
* *[\text { Table } 2 \text { here }]^{* *}
$$

Table 3 shows a breakdown of the specific formulas which participants had experienced. Modal categories were Touring Cars, Sports Cars or Saloons and Karting; not surprising as this is a common entry into the sport and single seater categories. Of these, 1 driver had F1 experience, 1 in WRC, 16 had experience in GT racing at European or World level, 17 in touring cars at national level or above and 20 had single seater experience at European or world level (excluding F1).

$$
\text { **[Table } 3 \text { here }]^{* *}
$$


The first objective was to examine the perceived importance and balance of fitness components for Motorsport. Table 4 shows the average percentage allocated to each fitness component. Cardiovascular (CV) endurance was rated the most important, followed by coordination, upper body muscular strength and endurance and reaction time. Analysis of these data showed a significant difference in response rates $\left(X^{2}(10)=18.753 .27, p<0.05\right)$, suggesting that participants viewed the various components as differentially important.

$$
* *[\text { Table } 4 \text { here }]^{* *}
$$

Table 5 shows a breakdown of these results categorised by participants' chosen formula. CV endurance was perceived as the most important on average in four of the categories, GT, single seater (equal with upper body strength), prototypes and rally/rally-cross although the rally category was skewed by a low number of participants (3) and, of those, one scored CV endurance at $90 \%$, much higher than any of the other participants. Other components perceived as high importance were coordination which was rated most important in Karting and touring/saloon and sports cars (and also rated high in single seaters and GT). Reaction time was rated of high importance particularly in Karting, Prototypes and touring/saloon and sports cars. Generally, however, all other fitness components were closely matched in perceived importance.

$$
* *[\text { Table } 5 \text { here }]^{* *}
$$

Participants' views on the genericity of these perceptions were also evaluated; in short, how much they felt that fitness demands would vary across formulas and how confident they were in this view. Notably, only one participant believed that the balance of fitness components "wouldn't vary between formulas" of racing, 88 believed them to be "largely similar but a few specific aspects may vary" whilst 28 believed they "completely changed depending on the formula". With regard to their confidence in the veracity of their views, 72 of the 111 
participants who answered this section indicated that it was "an informed view that they could justify", 20 were "certain", 4 were "50-50", 13 felt they were "possibly right" and 2 reported their results as "just a guess". These results showed a significant difference $\left(X^{2}(4)=\right.$ 166.7, $\mathrm{p}<0.001)$ suggesting that the majority of respondents were very confident in their viewpoint.

\section{Perceived role of fitness components}

The second objective was to investigate the perceived role of fitness components for drivers. Firstly, participants were asked to qualitatively justify their ratings to gain some understanding of possible reasons why. Some selected quotes to represent responses are presented in Table 6 .

$* *[\text { Table } 6 \text { here }]^{* *}$

Participants were also asked to distinguish between "hygiene factors" and "performance factors". Figure 1 shows the results from this question. Some components were clearly perceived as being more "hygiene factors" such as flexibility and muscular power. In contrast, three of the fitness components were clearly perceived as being "performance factors"; hand and foot speed, coordination and reaction time. Post hoc analysis by $\mathrm{X}^{2}$ showed each of these differences to be significant at the .05 level. Opinion on other components was more evenly split. CV endurance was perceived marginally (although non-significantly) more as being a "performance factor" upper body strength, core stability, leg strength, agility and balance were marginally perceived as being more "hygiene factors". Once again, these differences were non-significant.

**[Figure 1 here $]^{* *}$ 
As before, there was some diversity of opinion on genericity. Seven participants believed that this role of fitness components "would not vary at all" between formulas, 88 believed it would be "largely similar but a few specific aspects may vary" and 16 believed that it would "completely change depending on the formula". 68 participants also indicated that this was an "informed view that they could justify", 9 were "certain", 18 were "50-50", 9 felt they were "possibly right", 7 were "just a guess"; so overall, quite a strong confidence in the answers given which showed a significant difference $X^{2}(4)=135.7, p<0.001$.

\section{Sources of information used}

The third objective was to investigate the sources of information used in Motorsport for driver fitness and the level of confidence in these. Table 7 shows results from the three relevant questions. In frequency of use, data showed a varied 'thirst' for knowledge, across the sample, whilst for availability of information, the majority of participants indicated that there was "some information available but more would be beneficial" across all the sources listed. The notable exception was scientific journals, where the majority "didn't know"; in short, suggesting that this source wasn't used. Finally, views were also varied on the accuracy of information available from these sources. All difference in this section showed high levels of variability and were unsurprisingly non significant.

$$
* *[\text { Table } 7 \text { here }]^{* *}
$$

\section{Discussion}

Perceived importance, role and balance of fitness components.

On average across all formulas and in four out of six sub categories, CV endurance was rated by participants as the most important fitness component. Indeed, only in Karting was this component not considered in the top two most important factors. These findings do seem to 
fit with the available evidence. For example, single seater drivers have been found to experience significant $\mathrm{CV}$ stress, with similar $\mathrm{VO} 2$ and heart rate responses to running at 810 minute per mile pace [7]. However, there is no research into CV demands across different racing series with the exception of heart rate monitoring $[8,9]$, which is not a clear indication of physical demands due to the underlying psychological stress [10]. This is evidenced by the high heart rates recorded, even at low driving speeds [7]. Therefore, it is somewhat surprising that $\mathrm{CV}$ fitness was perceived of high importance across such a range of different formulas. However, looking at the range of responses in this field, it is clear that there were some extreme views with the highest importance given being $90 \%$ by an ex WRC driver and the lowest $0 \%$ given by a total of 5 participants, 4 drivers who had involvement in rally, Karting, single seaters and touring car/sports car or saloons and 1 Karting coach. Based on the mean data it appears more likely that the level of importance is around 10-25\% (cf. Table 5), depending on the formula.

Of course, as well as knowing what components of fitness participants believed to be important, it is also important to know why they thought this (cf. Tables 6). Interestingly, several responses mentioned heat and concentration as being reasons for the importance of CV training, whilst weight control was not mentioned. This could be down to the large number of participants in Touring Cars and Saloon Cars where the weight aspect may not be as important as in single seaters. From a mental perspective, research on the benefits of CV training for drivers is inconclusive, as the psychology literature has suggested a positive, but not significant, association between CV fitness and cognitive performance [20]. In the same study it was suggested that aerobic fitness is more likely to be the first event in a series that ultimately impacts cognitive performance. For example, it may help a driver cope with heat stress which is known to be associated with a deterioration of cognitive and psychomotor performance [21]. This is also inconclusive however, because, due to the environment, racing 
suit and helmet, even fit subjects have been found to be unable to thermoregulate under similar conditions [22]. Although fitter athletes [23] and those with a lower body fat percentage [24] can potentially tolerate higher body temperatures for longer. Additionally, as shown in table 1, different formula categories can have different amounts of races and test days in a season and as a result, differing amount of overseas travel. Further research would be beneficial to explore whether this may influence the importance of CV fitness for drivers' optimal recovery between races. Despite the relative scientific uncertainty, anecdotal reports of these $\mathrm{CV}$ benefits certainly seem to have filtered through the sport, as the majority of respondents rated this as a performance factor.

Coordination was also rated highly, second to CV endurance overall, highest in Karting and rated highly in the single seater, touring car and GT categories. However, similar to $\mathrm{CV}$ endurance, the range was very high, reflecting some individual contrasts. For example, in some of our selected responses (shown in Table 6.) several participants mentioned the importance of coordination for handling whereas others suggested it was not an area that could be trained outside of the car due to a lack of transferability. In similar fashion perhaps, reactions were also rated fairly highly amongst the categories, within the top four components but with a lower range and standard deviation than coordination, suggesting more of a consensus among participants. Once again, research on these aspects has been fairly inconclusive, partly due to the lack of tests specific to racing situations [11]. In single seater drivers, an association has been found between the reaction time and fine coordination [12], plus elite drivers have been found to perform better than junior drivers in strength, speed and coordination tests [11] suggesting that these are required to advance to higher levels. Clearly, devising tests and training procedures for these fitness components, as done in other sports [17], would be of great benefit, particularly as these were rated as the highest "performance factors" out of all the components. 
Upper body strength and strength endurance was rated highly across the majority of formulas, suggesting a general agreement amongst participants for the importance of this component. Perhaps unsurprising, as drivers need a strong neck and upper body in formulas with high $\mathrm{g}$ forces [12] and across other categories to reduce risk of cervical spine injuries from collisions [14]. Obviously, there will be differences in the specific cars across formulas; if they have power steering for example.

Of the remaining fitness components, core stability was ranked slightly higher than others. This has been thought to be a potentially important factor for injury prevention due to chronic exposure to vibrations and back pain being reported as the most common related injury in rally drivers [25]. Research has only found rally drivers to have a greater strength capacity of the trunk than physically active controls [12]; drivers in different formulas were found to have no difference [13]. From this survey, core stability was rated fairly similarly across formulas and not greater in rallying (although this was limited by a small number of participants in that category). It was perhaps slightly surprising that it wasn't rated of greater importance for Karting especially as drivers are not strapped in and can experience high lateral $\mathrm{G}$ forces [26].

It was somewhat surprising that leg strength and muscular power was rated of low importance throughout the different racing categories, especially as drivers are required to rapidly create high pedal pressures in some formulas such as single seaters [27], GT cars and some touring cars (as mentioned by some participants in Table 5). The low perceived importance could of course be due to low numbers of our participants racing in those specific cars that have those requirements. Alternatively, it could be representative of a lack of awareness how this mode of training could have a benefit to braking performance. 
These three components (upper body strength, core stability and leg strength) were similarly considered as being mainly "hygiene factors", understandable as only a certain amount of neck strength would be required for g force demands, upper body strength to control the car, core stability for injury prevention or leg strength to achieve a certain brake pressure. Of course, drivers may wish to train for strength in reserve, perhaps a possible reason why almost 50 of the participants in the survey believed them to be "performance factors". The other fitness components (flexibility, hand and foot speed, agility and balance) were generally perceived as holding a similar but low level importance. Again, however, there were individual differences as shown with some responses given for balance, speed and agility in Table 5. Flexibility, agility and balance were considered as being mainly "hygiene factors" whereas hand and foot speed was more "performance". Notably, CV endurance, upper body strength, leg strength, core stability, agility and balance were relatively closely balanced between performance and hygiene, suggesting that clarification of the specific role for fitness components would be beneficial for drivers, their coaches and fitness trainers.

Of course, if certain aspects are "hygiene factors", the key question is how much is required? For example, neck strength is an important hygiene factor; clearly vital for driver health and increasingly so as the $\mathrm{g}$ forces increase with more powerful formulas, with loads of $26 \mathrm{~kg}$ on the neck being reported in F1 [28]. Once again, however, there is a lack of accurate empirical data on exactly what the required levels across different formulas are. Should drivers train towards Wrestler, American Football or Rugby forward levels? Insufficient data exists to address this important question.

\section{Sources of information used}

In the frequency of use of different information sources, the sample of participants was fairly split. For example, 41 used anecdotal data from other drivers "regularly" and 18 "as much as 
possible". In contrast, 39 used this source "rarely" or "not at all". This did show that, along with the regular use of the internet as a source, a lot of information for fitness within Motorsport is based on "word of mouth". In short, cascade down from elite level drivers through other levels. The driver fitness specialist category had the highest number of participants using "as much as possible", but surprisingly 34 used "rarely". This could be down to several possible reasons such as accessibility or cost. Other fitness specialists who don't specialise in Motorsport may be more accessible in local training centres for a lot of drivers. In terms of the availability of information, there appeared to be an agreement amongst the majority of participants that there either wasn't enough or only some information available, emphasising the need for more peer-reviewed scientific based research in this field.

Interestingly, participants reported a high level of confidence in information gained from other drivers, again supporting the view that many rely on this for their training. Also, books, magazines and internet sources were reported as at least "some confidence"; which highlights that, ideally, these sources need to provide quality information. Of course, there is also potential for information from scientific sources to filter down into these sources, especially if presented in a simpler, easier to understand way that highlights the key points.

\section{Levels of confidence}

In general, participants' confidence in their views on fitness were quite high, with the majority indicating that they had "informed views that they could justify". However, considering this meant that they were not completely certain, in that 19 participants' confidence on the importance of fitness components and 34 participants' confidence on the roles of the components were 50/50 or less. This reflects a significant opportunity for practitioners working within Motorsport to provide clearer, proven information so that drivers can feel confident they are training in the best way possible for their sport. 
Despite the satisfactory response numbers there were limitations in this preliminary study and potential for bias within the data. The sample was small against the numbers involved in Motorsport worldwide. Furthermore, the differences in representation across the formulas (only three rally drivers for example) means that the sample's representativeness must be questioned. Furthermore, as highlighted, such differences have made some data points susceptible to artefactual influences from extreme positions. Also, the survey was not tested for reliability. Given these shortcomings, the study should be looked at as a preliminary description that highlights a problem. Certainly, any analyses, where these have been completed, are of necessity non-parametric. Nonetheless, the data serves to illustrate a significant gap in both the literature and applied practice.

\section{Recommendations and Next Steps}

Limitations notwithstanding, the results reflect reliance on anecdotal evidence in decision making on fitness for Motorsport. For example, the importance of CV fitness seems more a result of "what xxx does" (cf. the reported involvement of F1 drivers in Iron Man Triathlons) than a particular scientific logic. There is always a need for practitioners to challenge drivers when prescribing fitness, to change opinions and justify logic and reasoning underpinning this. This is important in implementing any change [29] and in managing expectancy in what the client thinks s/he will get from the programme. Next steps are clearly to increase the evidence base across different formulas and levels of driver.

\section{References}

1. AutoWeek. Still not convinced professional drivers are athletes? AutoWeek, October 2013; Vol. 63, Issue 12.

2. Ebben WP \& Suchomel TJ. Physical demands, injuries, and conditioning practices of stock car drivers. J Strength Cond Res 2012; 26(5): 1188-1198. 
3. The Telegraph. F1 Fitness: How to get in shape like Jenson Button. http://www.telegraph.co.uk/men/active/10693007/F1-fitness-how-to-get-in-shape-likeJenson-Button.html (2014, accessed 28 September 2017).

4. The Times. 'If you put Mo Farah in an F1 car he would be exhausted'. https://www.thetimes.co.uk/article/if-you-put-mo-farah-in-a-fl-car-he-would-beexhausted-c2qkkgfcv (2017, accessed September 2017).

5. Potkanowicz ES \& Mendel RW. The case for driver science in motorsport: a review and recommendations. Sports Med 2013; 43(7): 565-574.

6. Francheschini G, Terzini M \& Zanetti EM. Learning curves of elite car racers. Int J Sports Sci Coach. 2017; 12(2): 245-251.

7. Jacobs PL, Olvey SE, Johnson BM, et al. Physiological responses to high-speed, openwheel racecar driving. Med Sci Sports Exerc 2002; 34(12): 2085-2090.

8. Turner AP \& Richards H. Physiological and selective attention demands during an international rally motor sport event. BioMed Res Int 2015; 2015: 1-7.

9. Beaune B \& Durand S. Cardiac chronotropic adaptation to open-wheel racecar driving in young pilots. Int J of Perform Anal Sport 2011; 11(2): 326-235.

10. Schwaberger G. Heart rate, metabolic and hormonal responses to maxima psychoemotional and physical stress in motor car racing drivers. Int Arch Occup Environ Health 1987; 59(6): 579-604.

11. Raschner C, Platzer H-P \& Patterson C. Physical characteristics of experienced and junior open-wheel car drivers. J Sports Sci 2013; 31(1): 58-65.

12. Backman J, Häkkinen K, Ylinen J, et al. Neuromuscular performance characteristics of open wheel and rally drivers. J Strength Cond Res 2005; 19(4): 777-784.

13. Bauer H, Müller S, Pilz F, et al. Trunk extensor and flexor strength of long distance race car drivers and physically active controls. J Sports Sci 2010; 28(11): 1183-1187. 
14. Ebben W. Strength and conditioning for stock car racing. Strength Cond J 2010; 32(5): $16-27$.

15. Jutley RS \& Blow A. Motorsport Fitness Manual. Haynes Publishing. 2008, p.10.

16. Baechle TR \& Earle RW. Essentials of strength training and conditioning. $3^{\text {rd }}$ Edition. Human Kinetics. 2008, p.379.

17. Müller E, Benko U, Raschner C, et al. Specific fitness training and testing in competitive sports. Med Sci Sports Exerc 2000; 32(1): 216-220.

18. Di Salvo V, Baron R, Tschan H, et al. Performance Characteristics According to Playing Position in Elite Soccer. Int J Sports Med 2007; 28(3): 222-227.

19. Klarica AJ. Performance in motor sports. Br J Sports Med 2001; 35(5): 290-291.

20. Etnier JL, Nowell PM, Landers DM, et al. A meta-regression to examine the relationship between aerobic fitness and cognitive performance. Brain Res Rev 2006; S2: 119-130.

21. Rodrigues LOC \& Magalhāes FC. Car racing: in the heat of competition. Revista Brasileira de Medicina do Esporte 2004; 10(3): 216-219.

22. Windle CM \& Davies NJ. The Effect of fitness on performance in a hot environment wearing normal clothing and wearing protective clothing. Seventh International Conference on Environmental Ergonomics 1996: p209-212.

23. Cheung SS \& McLellan TM. Heat acclimation, aerobic fitness, and hydration effects on tolerance during uncompensable heat stress. J Appl Physiol 1998; 84(5): 1731-1739.

24. McLellan TM. The importance of aerobic fitness in determining tolerance to uncompensable heat stress. Comp Biochem Physiol 2001; 128(Part A): 691-700.

25. Mansfield NJ \& Marshall JM. Symptoms of musculoskeletal disorders in stage rally drivers and co-drivers. Br J Sports Med 2001; 35(5): 314-320. 
26. Yamakoshi T, Matsumura K, Yamakoshi Y, et al. Physiological measurements and analyses in motor sports: a preliminary study in racing kart athletes. Eur J Sports Sci 2010; 10(6): 397-406.

27. Küçükdurmaz F. Driver as a high level athlete. In: Doral M. (eds) Sports Injuries. Heidelberg, Berlin: Springer, 2012, pp.1121-1123.

28. Watkins ES. The Physiology and Pathology of Formula One Grand Prix Motor Racing. Clin Neurosurg 2006; 53:145-152.

29. Carson HJ \& Collins D. Refining and regaining skills in fixation/diversification stage performers: the Five-A Model. Int Rev Sport Exerc Psychol 2011; 4(2): 146-167. 
Figure 1. Number of participants who believed fitness components to be either a performance or hygiene factor

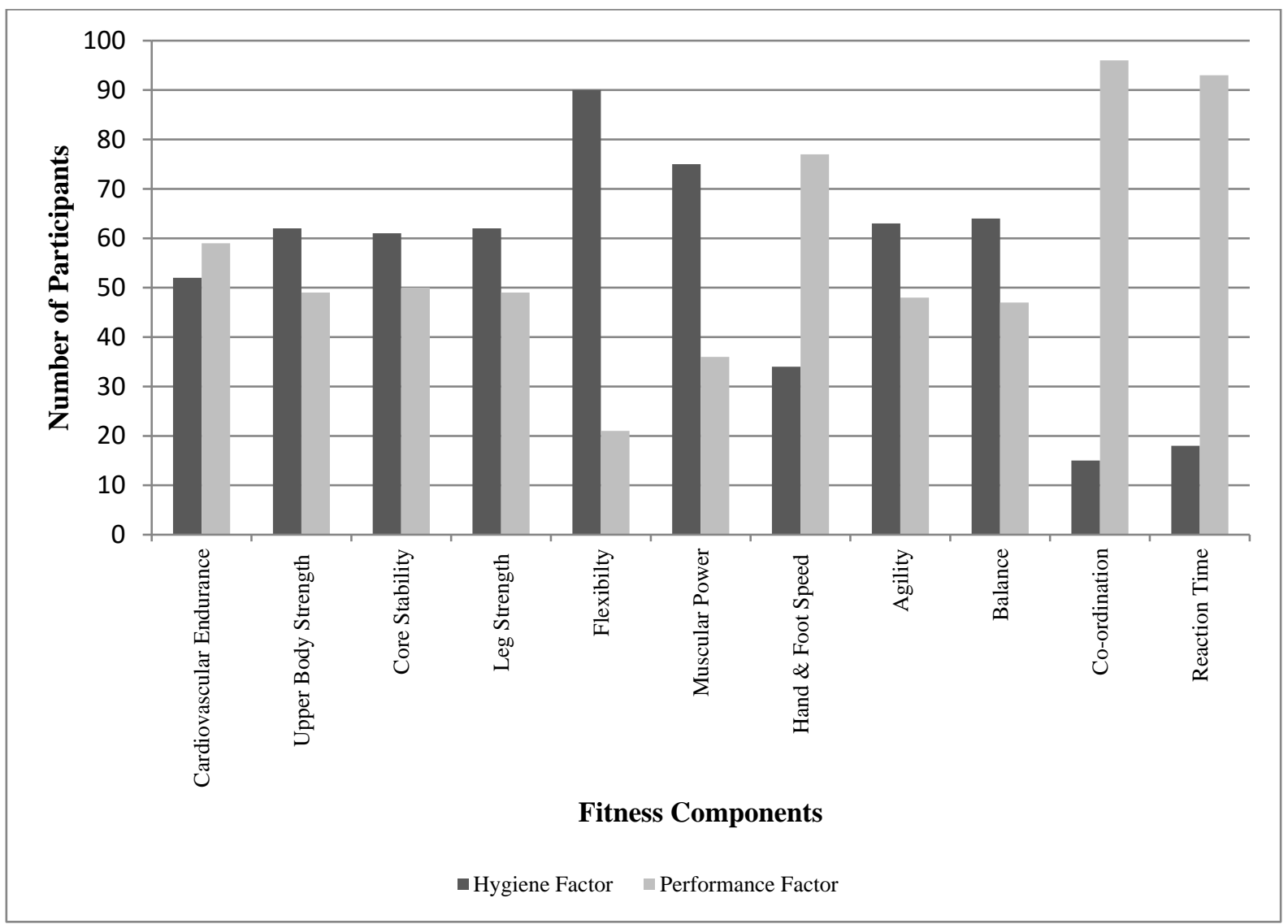


Table 1. Comparison of different categories and championships with Motorsport.

\begin{tabular}{|c|c|c|c|c|c|c|}
\hline Category & Series & $\begin{array}{c}\text { Race } \\
\text { Distance or } \\
\text { Time }\end{array}$ & $\begin{array}{l}\text { Number of } \\
\text { races in } \\
\text { season }\end{array}$ & $\begin{array}{l}\text { Approx. } \\
\text { Top } \\
\text { Speed } \\
(\mathrm{km} / \mathrm{h}) \\
\end{array}$ & $\begin{array}{c}\text { Max Lateral } \\
\text { Acceleration } \\
(\mathrm{G}-\text { force })\end{array}$ & $\begin{array}{l}\text { Power } \\
\text { Steering }\end{array}$ \\
\hline \multirow[t]{2}{*}{$\begin{array}{l}\text { Single } \\
\text { Seater }\end{array}$} & Formula One & $\begin{array}{l}305 \mathrm{~km}, \\
\text { typically } \\
75-120 \\
\text { minutes }\end{array}$ & 20 & $\begin{array}{l}\text { Up to } \\
370\end{array}$ & $\begin{array}{l}\text { Up to } \\
\text { approx. } 6.5\end{array}$ & Yes \\
\hline & GP3 & 30 minutes & 15 & 300 & 2.6 & No \\
\hline GT & $\begin{array}{l}\text { Blancpain } \\
\text { Endurance } \\
\text { (GT3) }\end{array}$ & $\begin{array}{l}3 \times 3 \text { hour } \\
\text { races, } \\
1 \times \\
1000 \mathrm{~km} \\
\text { race } \\
1 \times 24 \text {-hour } \\
\text { race } \\
3 \text { drivers } \\
\text { per car, } 1- \\
\text { hour stints }\end{array}$ & 5 & 290 & Unavailable & Yes \\
\hline \multirow{2}{*}{$\begin{array}{l}\text { Touring } \\
\text { Cars/Sports } \\
\text { Cars }\end{array}$} & $\begin{array}{l}\text { British } \\
\text { Touring Cars }\end{array}$ & $\begin{array}{l}\text { Typically } \\
16-25 \text { laps }\end{array}$ & 30 & 255 & $\begin{array}{l}\text { Approx. up } \\
\text { to } 2\end{array}$ & Yes \\
\hline & $\begin{array}{l}\text { Ginetta } \\
\text { Supercup }\end{array}$ & 20 minutes & 23 & 240 & Unavailable & Yes \\
\hline \multirow[t]{2}{*}{ Prototypes } & $\begin{array}{l}\text { World } \\
\text { Endurance } \\
\text { Championship } \\
\text { (LMP1) }\end{array}$ & $\begin{array}{l}8 \times 6 \text { hours } \\
1 \times 24 \\
\text { hours } \\
3 \text { drivers } \\
\text { per car }\end{array}$ & 9 & 330 & Approx. 3.5 & Yes \\
\hline & $\begin{array}{l}\text { Radical } \\
\text { European } \\
\text { Masters (SR8) }\end{array}$ & $\begin{array}{l}60 \text { minutes } \\
\text { Either } 1 \text { or } \\
2 \text { drivers }\end{array}$ & 21 & 275 & 2.2 & No \\
\hline \multirow[t]{2}{*}{$\begin{array}{l}\text { Rally \& } \\
\text { Rallycross }\end{array}$} & $\begin{array}{l}\text { World Rally } \\
\text { Championship }\end{array}$ & $\begin{array}{l}\text { Typically, } \\
\text { combined } \\
\text { stages are } \\
2.5-4 \\
\text { hours } \\
\end{array}$ & 13 & 200 & Unavailable & Yes \\
\hline & World RX & 4-6 laps & $\begin{array}{l}12 \text { (each } \\
\text { has } \\
\text { qualifying, } \\
\text { semi-final } \\
\text { and final) }\end{array}$ & 190 & Unavailable & Yes \\
\hline
\end{tabular}

Information is based on 2017 season regulations and data obtained from official championship and team websites 
Table 2. Participants' experience of roles in Motorsport

\begin{tabular}{lcccc}
\hline & $\mathrm{n}$ & Mean & $\mathrm{SD}$ & Range \\
\hline Driver & 151 & 10.33 & 8.89 & 54 \\
Fitness Trainer & 12 & 0.55 & 2.42 & 20 \\
Driver Coach & 38 & 1.19 & 2.78 & 12 \\
Mechanic or Engineer & 29 & 1.93 & 7.18 & 53 \\
\hline
\end{tabular}

Table 3. Specific formulas in which participants had experience

\begin{tabular}{lcc}
\hline \multicolumn{1}{c}{ Formula } & Drivers & Fitness Trainers \& coaches \\
\hline Karting & 81 & 25 \\
Rally \& Rallycross & 15 & 12 \\
Single Seater & 37 & 11 \\
Touring car, sports car, saloons & 88 & 24 \\
GT racing (including endurance) & 24 & 13 \\
Prototypes & 28 & 7 \\
\hline
\end{tabular}

Table 4. Perceived importance and balance of fitness components in racing drivers

\begin{tabular}{lccc}
\hline & \multicolumn{3}{c}{ All Formulas Combined $(\mathrm{n}=111)$} \\
\cline { 2 - 4 } & Mean $\%$ & $\mathrm{SD}$ & $\mathrm{R}$ \\
\hline Cardiovascular endurance & 17.5 & 13.2 & 90 \\
Upper body strength & 13.3 & 8.2 & 40 \\
Core stability & 8.3 & 5.0 & 30 \\
Leg strength & 7.3 & 6.0 & 40 \\
Flexibility & 4.3 & 4.0 & 25 \\
Muscular Power & 5.0 & 4.0 & 20 \\
Speed & 7.9 & 4.8 & 25 \\
Agility & 5.0 & 8.9 & 90 \\
Balance & 5.3 & 5.5 & 25 \\
Coordination & 14.2 & 11.1 & 75 \\
Reaction Time & 11.9 & 6.5 & 30 \\
\hline
\end{tabular}


Table 5. Perceived importance and balance of fitness components in racing drivers of different formulas of racing

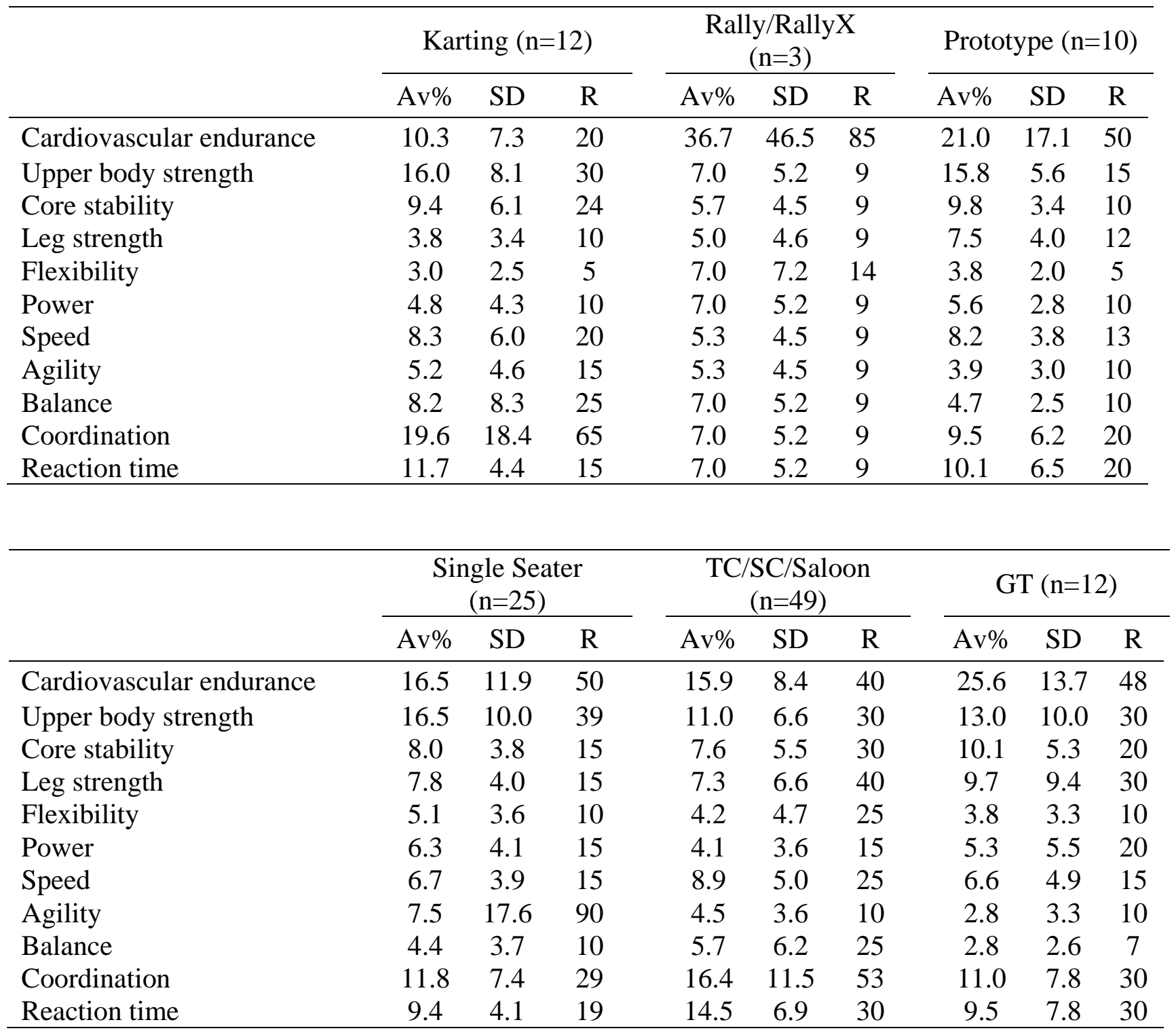

